\title{
High-dose erythropoietin population pharmacokinetics in neonates with hypoxic-ischemic encephalopathy receiving hypothermia
}

\author{
Adam Frymoyer', Sandra E. Juul' ${ }^{2}$ An N. Massaro ${ }^{3}$, Theo K. Bammler ${ }^{4}$ and Yvonne W. Wu ${ }^{5,6}$
}

BACKGROUND: High-dose erythropoietin (Epo) is a promising neuroprotective treatment in neonates with hypoxicischemic encephalopathy (HIE) receiving hypothermia. We evaluated the pharmacokinetics and dose-exposure relationships of high-dose Epo in this population to inform future dosing strategies.

METHODS: We performed a population pharmacokinetic analysis of 47 neonates with HIE treated with hypothermia who received up to six doses of Epo in two previous clinical trials. We compared the ability of different dosing regimens to achieve the target neuroprotective Epo exposure levels determined from animal models of hypoxic-ischemia (i.e., area under the curve during the first $48 \mathrm{~h}$ of treatment $\left(\mathrm{AUC}_{48 \mathrm{~h}}\right.$ ) $\left.140,000 \mathrm{mU} \mathrm{H}^{*} \mathrm{~h} / \mathrm{ml}\right)$.

RESULTS: Birth weight scaled via allometry was a significant predictor of Epo clearance and volume of distribution $(P<$ 0.001). After accounting for birth weight, variation in Epo pharmacokinetics between neonates was low (CV\% 20\%). All 23 neonates who received 1,000 U/kg every $24 \mathrm{~h}$ for the first $2 \mathrm{~d}$ of therapy achieved the target $\mathrm{AUC}_{48} \mathrm{~h} 140,000 \mathrm{mU} \mathrm{H}^{*} \mathrm{~h} / \mathrm{ml}$. No neonate who received a lower dosing regimen achieved this target. CONCLUSION: In neonates with HIE receiving hypothermia, Epo 1,000 U/kg every $24 \mathrm{~h}$ for the first $2 \mathrm{~d}$ of therapy resulted in consistent achievement of target exposures associated with neuroprotection in animal models.

$\mathbf{T}$ herapeutic hypothermia improves neurodevelopmental outcomes in neonates with moderate or severe perinatal hypoxic-ischemic encephalopathy (HIE), and is now the standard of care therapy for this population in first world countries (1). However, even with hypothermia, moderate to severe neurologic impairment or death is still common, occurring in up to $40 \%$ of neonates (2-6). The development of additional therapeutic treatment options for neonates with HIE is needed.

Recombinant human erythropoietin (Epo), a cytokine known more for its role in erythropoiesis, is a promising neuroprotective treatment in neonatal brain injury. In several animal models of neonatal hypoxic-ischemic brain injury, high-dose Epo has been shown to reduce brain injury and improve sensorimotor function (7-13). Epo appears to produce its neuroprotective effect through several mechanisms of action including antiapoptosis, anti-inflammatory, antioxidative, and neurotrophic effects (14). In line with animal studies, two small clinical studies found Epo improved short-term neurological outcomes in neonates with HIE not undergoing hypothermia $(15,16)$. Most recently, a placebo-controlled, randomized, double-blind phase II clinical study in neonates with HIE receiving hypothermia demonstrated Epo-treated patients had less brain injury on MRI and improved motor outcomes at 12 mo (17).

As Epo is advanced in clinical development for use in neonates with HIE receiving hypothermia, an understanding of its pharmacokinetics will be important. This is especially pertinent for neonates with HIE receiving hypothermia who frequently have alterations in drug pharmacokinetics and unique dosing needs (18-20). Additionally, much higher doses of Epo are needed for neuroprotection compared to doses used for treating anemia (100-500 U/kg/dose). For example, Epo 5,000 U/kg up to three doses was found to be most protective in animal models of neonatal brain injury (13). This dose results in a maximum concentration $\left(C_{\max }\right) \sim 10,000 \mathrm{mU} / \mathrm{ml}$ and an area under the plasma concentration-time curve during the first $48 \mathrm{~h}$ of treatment $\left(\mathrm{AUC}_{48}\right.$ ) of $\sim 140,000 \mathrm{mU} \mathrm{h}^{\star} / \mathrm{ml}$ in rats and serve as a potential exposure targets for neuroprotection in neonates (21). The objective of the current study was to evaluate the population pharmacokinetics of Epo in neonates with HIE receiving hypothermia using concentration data collected as part of previous phase I and phase II clinical studies, and to apply the information gained to support dosing strategies for future clinical efficacy studies.

\section{METHODS \\ General Study Design}

We performed a population pharmacokinetic analysis of Epo in neonates with HIE receiving therapeutic hypothermia using data collected as part of two previous prospective clinical trials: (i) a multicenter, open-label, dose-escalation study of Epo (“Phase I"; NCT00719407)

\footnotetext{
'Department of Pediatrics, Stanford University, Stanford, California; '2Department of Pediatrics, University of Washington, Seattle, Washington; ${ }^{3}$ Department of Neonatology, Children's National Health Systems, Washington, DC; ${ }^{4}$ Department of Environmental and Occupational Health Sciences, University of Washington, Seattle, Washington; ${ }^{5}$ Department of Neurology, University of California, San Francisco, California; ${ }^{6}$ Department of Pediatrics, University of California, San Francisco, California. Correspondence: Adam Frymoyer (frymoyer@stanford.edu)

Received 25 August 2016; accepted 28 December 2016; advance online publication 15 March 2017. doi:10.1038/pr.2017.15
} 
(22) and (ii) a multicenter, randomized double-blinded, placebocontrolled study of high-dose Epo ("Phase II"; NCT 01913340) (17). Each study received institutional review board approval at participating hospitals and was registered with the US Food and Drug Administration (Investigational New Drug 102 138). Informed consent was obtained for all patients.

\section{Patients}

Neonates were $\geq 36 \mathrm{wk}$ gestational age diagnosed with moderate to severe perinatal HIE, treated with therapeutic hypothermia (target temperature $33.5^{\circ} \mathrm{C}$ ). Criteria for hypothermia at each center were similar to the CoolCap (2) or National Institute of Child Health and Human Development studies (23). The duration of hypothermia therapy was planned for $72 \mathrm{~h}$. Additional exclusion criteria for both studies included: age at time of consent $>23.5 \mathrm{~h}$, congenital anomaly, suspected genetic syndrome, birth weight $<1,800 \mathrm{~g}$, head circumference $<2$ SDs below the mean, no indwelling intravenous line, or withdrawal of care being considered because of moribund condition.

\section{Erythropoietin Administration}

Epo was administered intravenously (IV) over $5 \mathrm{~min}$ followed by normal saline flush. In the phase I study, Epo was given every $48 \mathrm{~h}$ for a maximum of six doses. Four Epo doses were examined: $250(n=3)$, $500(n=6), 1,000(n=7)$, or $2,500(n=8) \mathrm{U} / \mathrm{kg} /$ dose. In the phase II study, neonates who were randomized to the treatment group $(n=$ 24) received Epo 1,000 U/kg every $24 \mathrm{~h}$ for three doses followed by every $48 \mathrm{~h}$ for two doses. For both studies, the first Epo dose was given within $24 \mathrm{~h}$ of birth.

\section{Pharmacokinetic Sampling}

In the phase I study, an intensive pharmacokinetic sampling strategy was utilized, and blood was collected 0 (predose), 0.5, 1, 3, 6, 12, 24, and $48 \mathrm{~h}$ after the first Epo dose. Additional blood samples were collected $0.5 \mathrm{~h}$ after the second dose, $48 \mathrm{~h}$ after the fifth dose, and $0.5 \mathrm{~h}$ after the sixth dose. In the phase II study, a sparse pharmacokinetic sampling strategy was utilized, and blood was collected 0 (predose) and $0.5 \mathrm{~h}$ after the first Epo dose and $48 \mathrm{~h}$ after the third dose. Neonates in the placebo group of the phase II study also had pharmacokinetic sampling performed at the same times relative to the placebo (normal saline) dose.

Plasma Epo concentrations were determined via the Quantikine IVD Human Epo Immunoassay (R\&D Systems, Minneapolis, MN) in the phase I study and the MSD Human Epo base kit (Meso Scale Diagnostics, Rockville, MD) in the phase II study. Samples were measured in duplicate and the average value was used. For the Quantikine assay, the lower limit of quantification is $2.5 \mathrm{mU} / \mathrm{ml}$, and within-run and between-run coefficients of variation were $\leq 11 \%$. For the MSD assay, the average lower limit of quantification is $1 \mathrm{mU} / \mathrm{ml}$, and withinrun and between-run coefficients of variation were $\leq 10 \%$ for for concentrations $>10 \mathrm{mU} / \mathrm{ml}$ and $<20 \%$ for concentrations $\leq 10 \mathrm{mU} / \mathrm{ml}$.

\section{Population Pharmacokinetic Analysis}

A population pharmacokinetic model was developed from the Epo concentration time data using the nonlinear mixed-effects modeling program NONMEM (Version VII, Icon Development Solutions Dublin, Ireland). Each Epo concentration was normalized by subtracting the median concentration in the placebo group of the phase II study using the closest sampling time point to account for any effect of endogenous erythropoietin. The first-order conditional estimation method with interaction was used throughout the model building and evaluation process. Both one-, two-, and three-compartment models with first-order elimination were examined, parameterized in terms of clearance $(\mathrm{CL})$, inter-compartmental clearance $(\mathrm{Q})$, central $\left(\mathrm{V}_{1}\right)$ and peripheral $\left(\mathrm{V}_{2}\right)$ volume of distribution. In addition, based on prior reports of nonlinear (i.e., dose dependent) kinetics in preterm infants receiving Epo, models incorporating Michaelis-Menten elimination parameterized in terms of $V_{\max }$ (maximum rate of elimination) and $K_{\mathrm{m}}$ (concentration at which the reaction rate is half of $V_{\max }$ ) were examined (24-26)

Interindividual variability in pharmacokinetic parameters was evaluated using an exponential error model. To model the residual (or intraindividual) variability, both additive and proportional error models were evaluated. Selection between structural models was based on the difference in the NONMEM objective function value $(\mathrm{OFV})$ and visual comparison of standard diagnostic plots. The difference in OFV between two models has an approximate $\chi^{2}$ distribution with degrees of freedom equal to the difference in the number of parameters between models. Significance was set at a decrease in OFV larger than 10.83 , corresponding to a $P<0.001$.

Once the structural pharmacokinetic model was established, the covariate model was developed. An allometric model of birth weight was first implemented to account for the influence of body size on clearance and volume of distribution. The allometric exponents were fixed to 0.75 for CL and Q and 1 for $V_{1}$ and $V_{2}(27,28)$. Next, the potential effect for maturational changes in neonates was explored using either a power function of gestational age (GA) or postmenstrual age as a predictor of CL and $\mathrm{V}_{1}$. Additional biologically and/ or clinically plausible covariates were also evaluated for their influence on pharmacokinetic parameters and included postnatal age, highest serum creatinine during treatment ( $\mathrm{SCr}$ ), highest alanine aminotransferase during treatment (ALT), biomarkers of severity of hypoxic-ischemic injury (e.g., lowest blood $\mathrm{pH}$, highest blood base deficit, APGAR score at $5 \mathrm{~min}$ ), small for gestational age status, and study enrolled (e.g., phase I vs. phase II). The effect of a continuous covariate on a parameter was modeled using a power function. Continuous covariates were scaled to their median values. Categorical covariates were modeled proportionally, that is, the fractional change in clearance when the categorical covariate was true.

The covariate model was built using a standard forward addition backward deletion procedure. Covariates were added in a stepwise manner to the model in the order of their reduction in the OFV. During forward stepwise addition, a covariate was allowed to enter the model as long as the decrease in OFV due to its addition was larger than 3.84, corresponding to a $P<0.05$. After the stepwise addition terminates, the model is pruned using backward elimination. Covariates were eliminated one at a time, until the removal of a covariate results in an OFV increase of more than 10.83, corresponding to a $P<0.001$.

To evaluate the accuracy and stability of the final pharmacokinetic model, a nonparametric bootstrap resampling method was performed using the NONMEM support software Perl-speaks-NONMEM (PsN, Version 3.6.2 University of Uppsala, Uppsala, Sweden). A total of 1,000 bootstrap datasets were generated from the original data set by repeated sampling with replacement, and the final pharmacokinetic model was used to estimate model parameters for each data set. In addition, the final pharmacokinetic model was assessed using an internal evaluation procedure by computing the normalized prediction distribution errors (NPDE) of 5,000 simulated datasets compared to the observed dataset $(29,30)$.

\section{Dose-Exposure Relationship}

To better understand Epo exposure after each dosing regimen, the cumulative area under the plasma concentration-time curve during the first $48 \mathrm{~h}\left(\mathrm{AUC}_{48 \mathrm{~h}}\right)$ and $7 \mathrm{~d}\left(\mathrm{AUC}_{7 \mathrm{~d}}\right)$ of dosing was calculated in NONMEM for each neonate by integrating Epo concentration in the central compartment. The maximum concentration $\left(C_{\max }\right)$ observed after the first dose was also summarized for this group. In addition, the percentage of children that achieved an $\mathrm{AUC}_{48 \mathrm{~h}} 140,000 \mathrm{mU} \mathrm{m}^{*} \mathrm{~h}$ $\mathrm{ml}$ and $C_{\mathrm{mat}} 10,000 \mathrm{mU} / \mathrm{ml}$ were calculated for each Epo dosing regimen. These targets were chosen based on exposures reported to be associated with neuroprotection in a rat model of neonatal hypoxic ischemic brain injury (21). Lastly, the Epo concentration-time course in a typical study patient (birth weight $3.4 \mathrm{~kg}$ ) was predicted using the final pharmacokinetic model for a $1,000 \mathrm{U} / \mathrm{kg}$ dose given per the phase I and phase II dosing schedule. Statistical analyses of the data and figure productions were performed using Microsoft Excel (Version 15 Redmond, WA) and STATA 13 (StataCorp LP, College Station, TX).

\section{RESULTS}

\section{Patients and Epo Concentrations}

In total, 48 neonates with HIE treated with hypothermia received high-dose Epo as part of a previous phase I or phase 
II clinical study $(17,22)$. Patient characteristics by study are shown in Table 1. Of the 24 neonates in the phase I study, the median (range) number of Epo doses was 5 (2-6). Nine patients received all six doses. Epo was discontinued early for the following reasons: discharged home $(n=10)$, lost IV access $(n=4)$, or had a protocol violation that prompted discontinuation of Epo $(n=1)$. Of the 24 neonates in the phase II study, 22 received all 5 doses, one received 4 doses, and one only received 1 dose due to redirection of care. This latter neonate did not have concentration data available for analysis, and therefore, 47 neonates contributed Epo concentration data. No concentrations during Epo administration were below the limit of quantification. One concentration drawn $48 \mathrm{~h}$ after third dose had the same reported time of collection as the time of administration of the fourth dose and was an outlier (concentration $6,699 \mathrm{mU} / \mathrm{ml}$ vs. next highest concentration at this time point $1,820 \mathrm{mU} / \mathrm{ml}$ ). Therefore, it was not included in the analysis. This resulted in a total of 265 Epo concentrations available for pharmacokinetic analysis.

\section{Population Pharmacokinetic Analysis}

The time course of Epo plasma concentration data was best described by a two-compartment model with first-order elimination and an exponential error model for inter-patient variability on CL. A two-compartment model was significantly better than a one-compartment model based on visual inspection of diagnostic posts and change in objective function $(\triangle \mathrm{OFV}-157 ; P<0.001)$. A three-compartment model did not provide any further statistical improvement. When

Table 1. Clinical characteristics of neonates with HIE who received hypothermia and high-dose Epo

\begin{tabular}{|c|c|c|}
\hline & $\begin{array}{l}\text { Phase I study } \\
\qquad(n=24)\end{array}$ & $\begin{array}{l}\text { Phase II study } \\
\quad(n=24)\end{array}$ \\
\hline $\begin{array}{l}\text { Gestational age at birth (completed), } \\
\text { weeks }\end{array}$ & $39(36-42)$ & $39(36-41)$ \\
\hline Birthweight, kg & $3.47(1.92-4.08)$ & $3.39(2.68-4.71)$ \\
\hline Female, $n(\%)$ & $12(50 \%)$ & $14(58 \%)$ \\
\hline \multicolumn{3}{|l|}{ APGAR } \\
\hline $5 \mathrm{~min}$ & $3(0-8)$ & $3(0-7)$ \\
\hline $10 \mathrm{~min}$ & $4(0-8)$ & $5(1-8)$ \\
\hline First arterial or capillary $\mathrm{pH}$ & $6.90(6.72-7.23)$ & $6.91(6.70-7.29)$ \\
\hline Base deficit, $\mathrm{mmol} / \mathrm{l}$ & $-16(-27--10)$ & $-17(-33--2)$ \\
\hline $\mathrm{Cr}_{\text {max' }} \mathrm{mg} / \mathrm{dl}$ & $0.9(0.6-2.8)$ & $1.0(0.6-3.5)$ \\
\hline $\mathrm{Cr}_{\max }>1.4 \mathrm{mg} / \mathrm{dl}, n(\%)$ & $1(4 \%)$ & $5(21 \%)$ \\
\hline $\mathrm{ALT}_{\text {max }^{\prime}} \mathrm{U} / \mathrm{I}$ & $65(13-692)$ & $62(14-926)$ \\
\hline $\mathrm{ALT}_{\max }>100 \mathrm{U} / \mathrm{l}, n(\%)$ & $8(33 \%)$ & $10(42 \%)$ \\
\hline Intubation > $12 \mathrm{~h}, n(\%)$ & $16(67 \%)$ & $17(71 \%)$ \\
\hline Clinical seizure, $n(\%)$ & $9(38 \%)$ & $8(33 \%)$ \\
\hline Hypotension requiring inotrope, $n$ (\%) & $10(42 \%)$ & $9(38 \%)$ \\
\hline Death during hospitalization, $n(\%)$ & $0(0 \%)$ & $2(8 \%)$ \\
\hline
\end{tabular}

All data are median (range) or number of patients (\%).

$\mathrm{ALT}_{\text {max' }}$ maximum alanine aminotransferse during study period; $\mathrm{Cr}_{\text {max' }}$ maximum serum creatinine during study period. nonlinear Michaelis-Menten elimination was examined, the model in essence reduced to a first-order elimination model based on the estimate of $K_{\mathrm{m}}(=1,520,000 \mathrm{mU} / \mathrm{ml})$ being much higher than Epo plasma concentrations observed. Estimates of the interpatient variability on $\mathrm{V}_{1}$ approached zero and could not be estimated with any precision using the available data. Removal of this random effect on $\mathrm{V}_{1}$ did not change the statistical fit of the model or the goodness-of-fit plots, and therefore, it was removed from the final model. The residual variability (or intrapatient variability) was best described by a proportional error model.

Once the structural model was established, the covariate model was developed. The addition of birth weight scaled using fixed allometric exponents significantly improved the model $(\triangle \mathrm{OFV}-53.8 ; P<0.001)$. If the exponent defining the allometric relationship of birthweight on CL and Q was allowed to be estimated, a value of 1.27 was found $(\triangle \mathrm{OFV}-7.7$ compared to model with a fixed exponent of $0.75 ; P<0.01$ ). The marginal improvement in statistical fit along with the limited sample size and narrow range of birth weight in the current study did not support updating the exponent from 0.75 , which has strong theoretical justification and a large amount of prior knowledge to support $(27,28)$.

After incorporating birth weight in the model, only postnatal age was identified as a significant predictor of CL $(\triangle \mathrm{OFV}$ $-8.8 ; P<0.05)$ during forward stepwise addition. However, during backward elimination, this covariate did not meet the statistical criteria of $P<0.001$ for remaining in the final model. In addition, the exponent defining the relationship between postnatal age and CL could not be estimated with any precision, and the $95 \%$ confidence interval of the exponent crossed 0 (i.e., postnatal age had no effect on CL). Therefore, postnatal age was removed from the final model. No other significant covariates were identified.

The final population pharmacokinetic model parameter estimates are presented in Table 2. In general, observed vs. population predicted concentrations showed no systemic bias, and the weighted residuals were homogeneously scattered (Figure 1; Supplementary Figure S1 online). Observed and model predicted concentrations for several individual patients are also shown in Supplementary Figure S2 online. The parameter estimates as found by bootstrap were in agreement with those obtained by the final population pharmacokinetic model (Table 2), indicating reliability of the final model estimates. Internal model evaluation also demonstrated that the final model performed well in describing the observed data. The NPDE mean was 0.07 (95\% CI: $-0.05-0.19)$ and variance was 0.98 (95\% CI: $0.78-1.2)$. The theoretical NPDE mean is zero with a variance 1.0. The percentage of observations that fell inside the theoretical $90 \%$ prediction interval were $89.4 \%$. In addition, there were no major trends in NPDE across predicted concentration, time, or birth weight (Supplementary Figure S3 online).

Lastly, the endogenous erythropoietin levels in the placebo group of the Phase II study were median (IQR) 12.2 (8.9-42.6) $\mathrm{U} / \mathrm{l}$, which are very low relative to concentrations resulting 


\section{Articles | Frymoyeretal.}

after exogenous high-dose Epo. As a result, normalizing the Epo concentrations after high-dose Epo to endogenous erythropoietin levels had very little impact on the model. If "raw" Epo concentrations were used instead in the final model, the model parameters were essentially the same.

\section{Dose-Exposure Relationship}

Epo exposure following dosing in each neonate was calculated using the final pharmacokinetic model. AUC during the first $48 \mathrm{~h}$ of dosing $\left(\mathrm{AUC}_{48 \mathrm{~h}}\right)$ increased with dose amount and more frequent administration (Figure 2a; Table 3). For example, at a dose of $1,000 \mathrm{U} / \mathrm{kg}$ the median (IQR) $\mathrm{AUC}_{48 \mathrm{~h}}$ was 114,180 $(102,850-120,650) \mathrm{mU}{ }^{\star} \mathrm{h} / \mathrm{ml}$ for those receiving every $48 \mathrm{~h}$ and $191,300(177,510-209,160) \mathrm{mU}$ h/ml for those receiving every

Table 2. Final Epo population pharmacokinetic model parameter estimates and bootstrap results for a typical $3.4 \mathrm{~kg}$ neonate with HIE receiving hypothermia

\begin{tabular}{lccccc}
\hline $\begin{array}{l}\text { Population } \\
\text { pharmacokinetic } \\
\text { parameters }\end{array}$ & \multicolumn{2}{c}{ Final model } & \multicolumn{2}{c}{ Bootstrap $(\boldsymbol{n}=\mathbf{1 , 0 0 0})$} \\
\cline { 2 - 3 } \cline { 5 - 6 } & Estimate & \%SE & Median & $\mathbf{9 5 \% ~ C l}$ \\
\hline $\mathrm{CL}(\mathrm{L} / \mathrm{h})^{1}$ & 0.0289 & 4.5 & 0.0288 & $0.0263-0.0317$ \\
$\mathrm{~V}_{1}(\mathrm{~L})^{2}$ & 0.250 & 4.1 & 0.250 & $0.230-0.270$ \\
$\mathrm{~V}_{2}(\mathrm{~L})^{3}$ & 0.326 & 10.9 & 0.328 & $0.266-0.408$ \\
$\mathrm{Q}(\mathrm{L} / \mathrm{h})^{4}$ & 0.0308 & 13.5 & 0.0315 & $0.0218-0.0398$ \\
Interpatient variability & & & & \\
$\mathrm{CL}, \% \mathrm{CV}$ & $20.1 \%$ & 32.4 & $19.5 \%$ & $9.6-25.1 \%$ \\
Residual variability, \%CV & $35.1 \%$ & 13.4 & $35.0 \%$ & $30.2-39.4 \%$ \\
\hline
\end{tabular}

$\mathrm{CL}$, clearance; $\mathrm{V}_{1}$, volume of distribution central compartment; $\mathrm{V}_{2}$, volume of distribution peripheral compartment; $Q$, intercomparmental clearance; $\% C V$, coefficient of variation $\times$ $100 ; \%$ SE, relative standard error $\times 100 ; 95 \% \mathrm{Cl}$, Bootstrap parameter estimate at the 2.5 th and 97.5 th percentiles.

$$
\begin{aligned}
& { }^{1} C L(L / h)=0.0289 \times\left(\frac{\text { Weight }}{3.4 \mathrm{~kg}}\right)^{0.75} \quad{ }^{2} V_{1}(L)=0.250 \times\left(\frac{\text { Weight }}{3.4 \mathrm{~kg}}\right) \\
& { }^{4} Q(L / h)=0.0308 \times\left(\frac{\text { Weight }}{3.4 \mathrm{~kg}}\right)^{0.75} \quad{ }^{3} V_{2}(L)=0.326 \times\left(\frac{\text { Weight }}{3.4 \mathrm{~kg}}\right)
\end{aligned}
$$

a

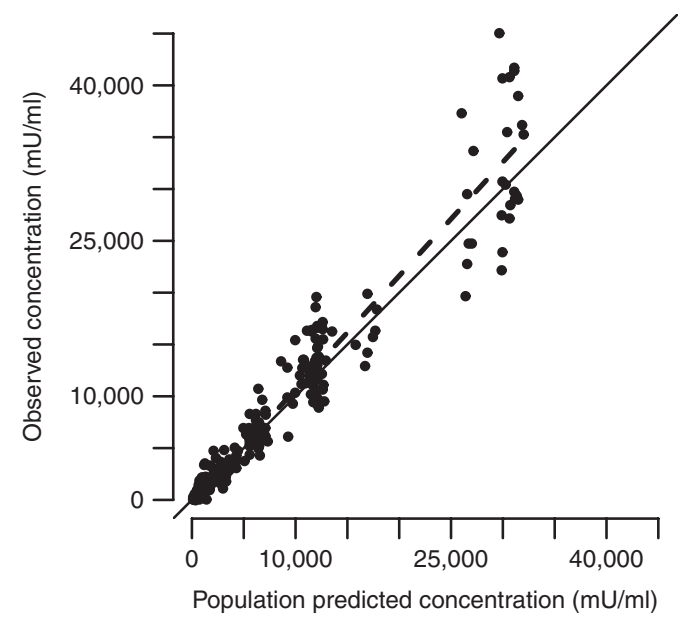

$24 \mathrm{~h}$. For a given dosing regimen, variability in $\mathrm{AUC}_{48} \mathrm{~h}$ was low (CV\% 7.8-12.1\%). The $\mathrm{AUC}_{48 \mathrm{~h}}$ target of $140,000 \mathrm{mU} \mathrm{U}^{\star} \mathrm{h} / \mathrm{ml}$ was not achieved in any neonate $(n=0 / 7)$ who received a dose of $1,000 \mathrm{U} / \mathrm{kg}$ every $48 \mathrm{~h}$, however all neonates $(n=23 / 23)$ who received a dose of $1,000 \mathrm{U} / \mathrm{kg}$ every $24 \mathrm{~h}$ for the first 2 $\mathrm{d}$ achieved this target. $C_{\max }$ after the first dose increased with dose amount (Figure 2b; Table 3). The $C_{\max }$ target of 10,000 $\mathrm{mU} / \mathrm{ml}$ was only achieved in neonates who received doses of $1,000 \mathrm{U} / \mathrm{kg}(n=25 / 30 ; 86 \%)$ or $2,500 \mathrm{U} / \mathrm{kg}(n=7 / 7 ; 100 \%)$.

The cumulative AUC during the first $7 \mathrm{~d}$ of dosing $\left(\mathrm{AUC}_{7 \mathrm{~d}}\right)$ are also shown in Table 3. At a dose of $1,000 \mathrm{U} / \mathrm{kg}$ every $24 \mathrm{~h}$ for 3 doses followed by every $48 \mathrm{~h}$, the additional dose during the first $2 \mathrm{~d}$ of therapy in the phase II study resulted on average in a 19\% higher exposure over the first $7 \mathrm{~d}$ compared to the neonates in the phase I study who received $1,000 \mathrm{U} / \mathrm{kg}$ every $48 \mathrm{~h}$. The predicted Epo concentration-time courses in a typical study neonate with HIE receiving 1,000 U/kg per the phase I and phase II dosing schedule are shown in Figure 3. By day 6 of therapy, Epo concentrations are similar between the two dosing schedules with minimal residual exposure from the additional dose given during the first $2 \mathrm{~d}$ of therapy per the phase II dosing schedule.

\section{DISCUSSION}

This is the first study to describe the population pharmacokinetics of high-dose Epo in neonates with HIE receiving hypothermia. Epo pharmacokinetics was adequately described by a two-compartment model with linear elimination. A major study finding was that after accounting for the effect of birth weight, the pharmacokinetics of Epo was generally consistent between neonates and interpatient variation was small. The clinical implication of these findings is that weight-based Epo dosing (i.e., $\mathrm{U} / \mathrm{kg}$ ) will result in similar exposure for a given dose across neonates with HIE receiving hypothermia.

Neonates with HIE receiving hypothermia represent a unique population from a pharmacologic perspective, and the direct examination of the pharmacokinetics of drugs used in this

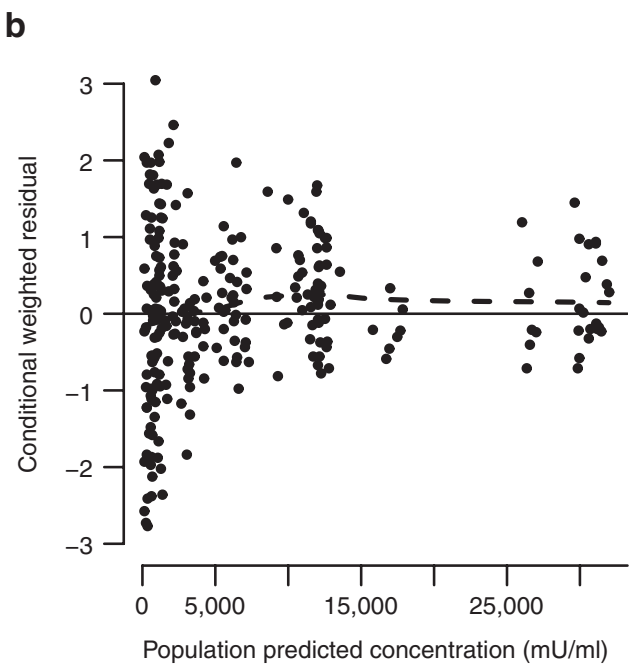

Figure 1. Goodness of fit plots. Observed vs. population predicted concentrations (a) and conditional weight residual vs. population predicted concentrations (b) for the final pharmacokinetic model. Solid line indicates the line of unity. Dashed line indicates loess smooth. 
population will be helpful to guide dosing (31). In the current study, we developed a population pharmacokinetic model of Epo in neonates with HIE receiving hypothermia. Weight was identified to be a significant predictor of both clearance and volume which is consistent with our current understanding on the importance of body size as a primary covariate impacting
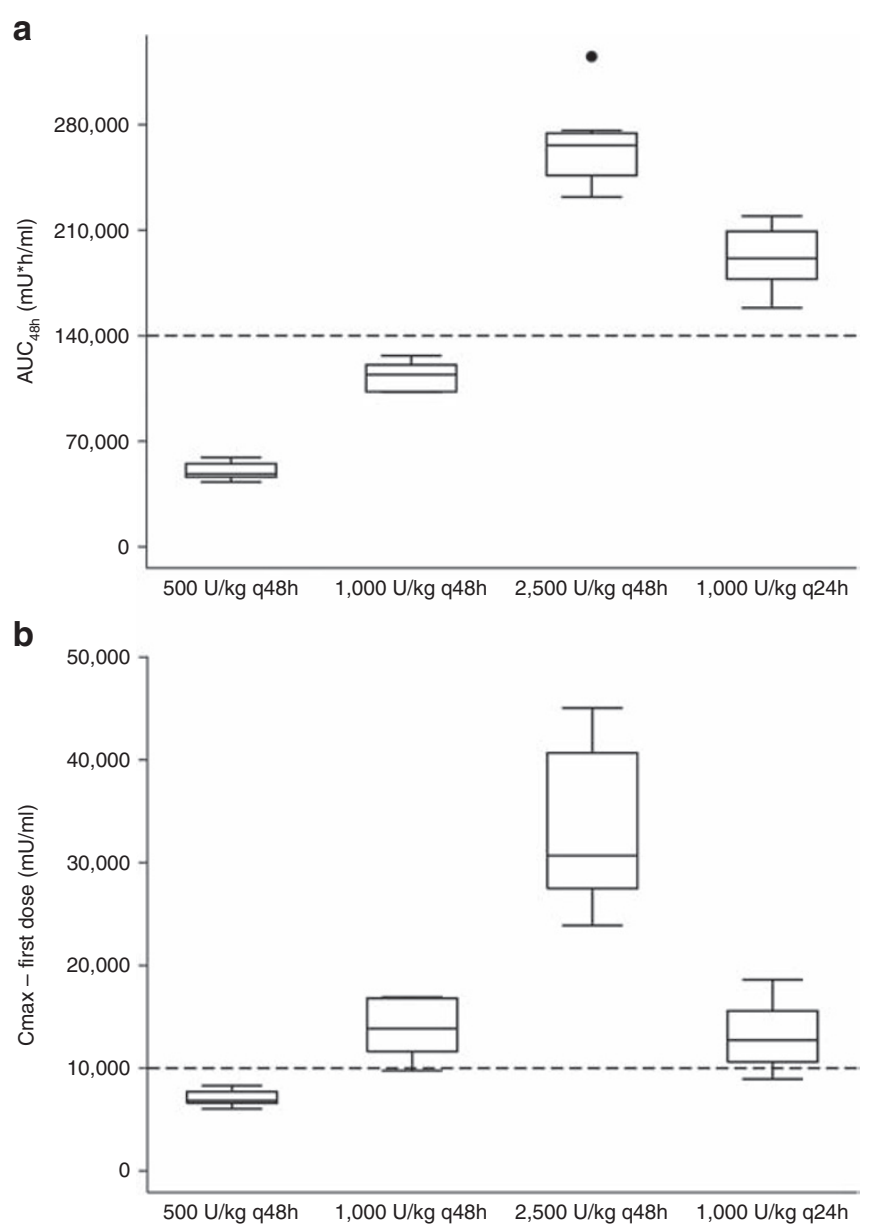

Figure 2. Epo exposure in neonates with HIE receiving hypothermia by Epo dosing regimen: $\mathrm{AUC}_{48 \mathrm{~h}}(\mathbf{a})$ and $\mathrm{C}_{\max }$ after first dose (b) Boxplots represent neonates who received dosing regimens of $500(n=6), 1,000(n=7)$, $2,500(n=8) \mathrm{U} / \mathrm{kg}$ every $48 \mathrm{~h}(\mathrm{q} 48 \mathrm{~h})$ and $1,000 \mathrm{U} / \mathrm{kg}$ every $24 \mathrm{~h}$ ( $n=23$; q24h). The dosing regimen of $250 \mathrm{U} / \mathrm{kg}$ every $48 \mathrm{~h}(n=3)$ is not shown. Dashed lines reference target $A U C_{48} \mathrm{~h} 140,000 \mathrm{mU} * \mathrm{~h} / \mathrm{ml}$ and $C_{\max }$ concentration $10,000 \mathrm{mU} / \mathrm{ml}$. the pharmacokinetics of drugs in infants and children (27). After incorporating weight, no impact of developmental maturation on Epo clearance was found using gestational age as a surrogate. The elimination pathway of Epo is not completely understood, but traditional routes of hepatic metabolism and renal elimination, for which maturational changes in neonates are well-established, are likely not involved (32). Instead Epo clearance appears more likely to be mediated via receptormediated uptake and degradation by hematopoietic and possibly even nonhematopoietic cells $(33,34)$. The current study likely had low power for detecting a maturational effect on this process as only neonates with gestational age $>36$ wk qualify for hypothermia and were therefore studied. The ontogeny of this complex physiologic regulatory process remains to be elucidated.

For a typical study neonate with HIE receiving hypothermia, Epo clearance was $8.3 \mathrm{ml} / \mathrm{h} / \mathrm{kg}$. This is lower than a previously reported clearance of $13.1 \mathrm{ml} / \mathrm{h} / \mathrm{kg}$ in preterm neonates who were not undergoing hypothermia and received high-dose Epo $1,000 \mathrm{U} / \mathrm{kg}$ (26). The difference in Epo clearance may be due in part to maturational effects, organ dysfunction associated with global hypoxic insult, the effect of hypothermia, and/or other

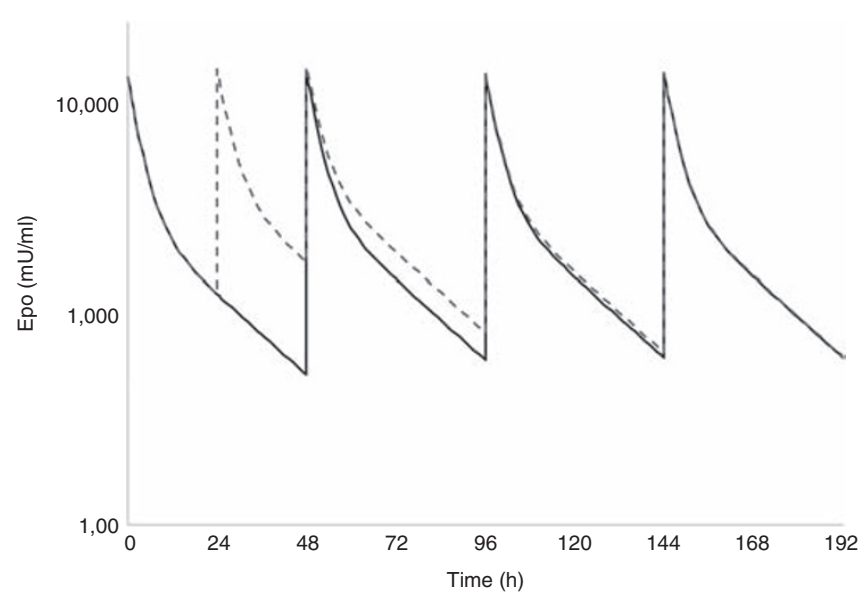

Figure 3. Predicted erythropoietin concentration-time course during the first week of therapy in a typical study neonate with HIE receiving 1,000 U/ $\mathrm{kg}$ per the phase I and phase II dosing schedule. The dosing schedule was every $48 \mathrm{~h}$ in the phase I study (solid line) and every $24 \mathrm{~h}$ for three doses followed by every $48 \mathrm{~h}$ in the phase II study (dashed line). The final population pharmacokinetic model was used to predict all concentrations for a neonate weighing $3.4 \mathrm{~kg}$.

Table 3. Erythropoietin exposure in neonates with HIE receiving hypothermia after high-dose Epo

\begin{tabular}{|c|c|c|c|c|}
\hline & Phase I & Phase I & Phase I & Phase II \\
\hline & $500 \mathrm{U} / \mathrm{kg}(n=6)$ & $1,000 \mathrm{U} / \mathrm{kg}(n=7)$ & $2500 \mathrm{U} / \mathrm{kg}(n=8)$ & $1,000 \mathrm{U} / \mathrm{kg}(n=23)$ \\
\hline Dose frequency & Every $48 \mathrm{~h}$ & Every $48 \mathrm{~h}$ & Every $48 \mathrm{~h}$ & $\begin{array}{c}\text { Every } 24 \mathrm{~h} \times 3 \\
\text { doses then every } 48 \mathrm{~h}\end{array}$ \\
\hline$C_{\max }$ after first dose $(\mathrm{mU} / \mathrm{ml})$ & $6,844(6,596-7,705)$ & $13,851(11,613-16,798)$ & $30,691^{a}(27,493-40,677)$ & $12,730(10,609-15,574)$ \\
\hline AUC $_{48 \mathrm{~h}}\left(\mathrm{mU}^{*} \mathrm{~h} / \mathrm{ml}\right)$ & $48,280(46,180-55,071)$ & $114,180(102,850-120,650)$ & $266,260(246,310-274,250)$ & $191,300(177,510-209,160)$ \\
\hline AUC $_{7 \mathrm{~d}}\left(\mathrm{mU} \mathrm{U}^{*} \mathrm{~h} / \mathrm{ml}\right)$ & $210,950^{b}(190,840-239,050)$ & $483,830^{c}(426,120-510,560)$ & $1,107,500(1,007,600-1,145,800)$ & $541,610(491,850-599,010)$ \\
\hline
\end{tabular}




\section{Articles | Frymoyeretal.}

unknown factors. As a result of this difference in clearance, neonates with HIE receiving hypothermia will have on average more than 50\% higher exposure after an Epo dose of 1,000 U/kg than preterm neonates. Similar to our study findings, lower clearance of darbepoetin (a long-acting erythropoiesis-stimulating agent) was also found in neonates with HIE receiving hypothermia compared to preterm neonates $(35,36)$.

Nonlinear elimination of Epo has previously been reported in preterm neonates (24-26). However, we were unable to appreciate nonlinear elimination of Epo in the current pharmacokinetic model. Nonlinear elimination is most often seen for drugs when saturation of a major elimination pathway occurs. Since all neonates in our analysis received frequent, high-dose Epo and approximately $80 \%(n=39 / 47)$ received doses $\geq 1,000$ $\mathrm{U} / \mathrm{kg}$, nearly complete saturation of an elimination pathway (i.e., Epo receptor-mediated uptake and degradation $(33,34)$ ) could have been present and other nonsaturable elimination pathways may have become important. In addition, the effect of hypothermia and hypoxic injury on the elimination pathway(s) of Epo is not known but could have impacted the pharmacokinetics. This may be supported by the lower clearance in neonates with HIE receiving hypothermia compared to preterm neonates as described above. Lastly, linear elimination has also been described for darbepoetin in neonates with HIE receiving hypothermia in a previous population pharmacokinetic analysis (35).

Epo is traditionally used in preterm neonates for the treatment of anemia of prematurity. Insight into its nonhematopoietic effects including antiapoptosis, antiinflammatory, antioxidative, and neurotrophic properties in the brain have led to its development as an exciting potential neuroprotective therapy in neonates with HIE (14). In animal models of hypoxic-ischemic brain injury, treatment with Epo has repeatedly demonstrated improved neurologic outcomes and has been shown to be safe (7-13). For neuroprotection, much higher doses of Epo are required (1,000-5,000 U/kg/ dose) compared with doses used for the treatment of anemia (100-500 U/kg/dose). This is likely due in part to the fact that Epo is a large glycosylated protein (molecular weight $>30,000$ Daltons) leading to low permeability across the blood-brain barrier (BBB). However, hypoxic-ischemic injury is known to disrupt the $\mathrm{BBB}$ and increase the permeability of large proteins (37-39). Indeed, concentrations of Epo are higher in the brain in rats treated with high-dose Epo after expose to hypoxicischemic injury (21). Additionally, cerebral spinal fluid/brain concentrations of Epo have been found to strongly correlate with plasma exposure $(21,40,41)$. Therefore, an understanding of Epo pharmacokinetics in plasma will be helpful to guide the clinical development and dosing of high-dose Epo in neonates with HIE. This is especially true given the impracticality of sampling brain concentrations of Epo in neonates.

The current pharmacokinetic analysis took advantage of Epo plasma concentrations measured as part of two prospective clinical studies conducted in neonates with HIE receiving hypothermia $(17,22)$. The first was a phase I dose-escalation study in 24 neonates, which in addition to demonstrating safety, helped shed initial light on the dose needs in this population. In this phase I study, a dose of $1,000 \mathrm{U} / \mathrm{kg}$ every $48 \mathrm{~h}$ was found to most closely approximate the Epo exposure associated with neuroprotection in rats $\left(\mathrm{AUC}_{48 \mathrm{~h}} \sim 140,000\right.$ $\mathrm{mU}{ }^{\star} \mathrm{h} / \mathrm{ml} ; C_{\max } \sim 10,000 \mathrm{mU} / \mathrm{ml}$ ) (21). However, the exposure in neonates with this dosing was still slightly lower than the target for neuroprotection in rats, and no neonates achieved an $\mathrm{AUC}_{48} \geq 140,000 \mathrm{U}^{\star} \mathrm{h} / \mathrm{l}$ during the first $48 \mathrm{~h}$ of therapy. Accordingly, in the phase II randomized controlled study, the dosing interval was shortened to $1,000 \mathrm{U} / \mathrm{kg}$ every $24 \mathrm{~h}$ for the first $2 \mathrm{~d}$ of therapy in an attempt to ensure adequate exposures early on after injury. In the phase II study, a clinical benefit was seen in the Epo treated group with this dosing strategy in terms of brain MRI findings and motor function at 12 mo (17). The current pharmacokinetic analysis of concentration data from this phase II study supports the more frequent dosing regimen, since all neonates achieved (and exceeded) the $\mathrm{AUC}_{48 \mathrm{~h}}$ target of $140,000 \mathrm{mU}$ h/ml during the first $48 \mathrm{~h}$. In addition, variation in exposure between neonates was low. Taken together, further confidence is gained in moving the same Epo dosing strategy forward for the planned large phase III efficacy study of neonates with HIE receiving hypothermia (NCT\# 02811263).

The optimal duration of Epo dosing after hypoxic-ischemic injury is not known, but prolonged Epo exposure after injury may be beneficial. In animal models, rats treated with three 5,000 U/kg doses of Epo during the first week after injury had a greater benefit than those treated with just a single dose (13). Epo has even been shown to be effective when started more than 2-3 d after brain injury (42-44). To gain an estimate of the overall exposure in rats after three $5,000 \mathrm{U} / \mathrm{kg}$ doses of Epo, we calculated a cumulative AUC of $\sim 350,000 \mathrm{mU}$ h/ml (= total dose $\div$ clearance $=15,000 \mathrm{U} /$ $\mathrm{kg} \div 0.042 \mathrm{l} / \mathrm{h} / \mathrm{kg}$ ) (21). In our phase I and phase II studies of Epo, all neonates that received at least four doses of 1,000 $\mathrm{U} / \mathrm{kg}$ had an $\mathrm{AUC}>430,000 \mathrm{mU} \mathrm{H}^{\star} \mathrm{h} \mathrm{ml}$ during the first $7 \mathrm{~d}$ of therapy. Darbepoetin, an erythropoiesis stimulating agent with a longer circulating half-life, is also being investigated for neuroprotection in HIE (45). In contrast, a $10 \mu \mathrm{g} / \mathrm{kg}$ dose of darbepoetin in neonates with HIE receiving hypothermia resulted in an erythropoietin AUC $\sim 180,000 \mathrm{mU}$ h/ml during the first $7 \mathrm{~d}$ of treatment (45). Further understanding regarding the optimal duration of dosing and exposure of erythropoiesis-stimulating agents in neonates will be helpful as clinical development advances.

A limitation to our study is the narrow range of gestational age of neonates. This limitation is inherent to studying neonates with HIE as a gestational age $>36 \mathrm{wk}$ is current criteria to qualify for hypothermia as based on the original randomized controlled trials. If future clinical studies support expanding hypothermia to preterm neonates with HIE, caution is warranted in terms of extrapolating the developed population pharmacokinetic model and study findings to the preterm population. An additional limitation is the exposure matching approach utilized. The plasma $\mathrm{AUC}_{48 \mathrm{~h}}$ and $\mathrm{C}_{\max }$ targets were extrapolated from animal models of hypoxic-ischemic brain 
injury, and the exposure needs in neonates may differ. We were also only able to examine the exposure of Epo in plasma. The importance of achieving specific Epo exposures in the brain is not known but may be critical. Nonetheless, the exposure matching approach used in this study represents an evidenced based pharmacokinetic framework to evaluate Epo dose needs in neonates with HIE receiving hypothermia.

\section{Conclusions}

In neonates with HIE receiving hypothermia, Epo pharmacokinetics were significantly influenced by birth weight. After accounting for birth weight, variation in pharmacokinetics between neonates was low, and no other significant predictors were found. A dose of $1,000 \mathrm{U} / \mathrm{kg}$ every $24 \mathrm{~h}$ for the first $2 \mathrm{~d}$ of therapy followed by every $48 \mathrm{~h}$ for $4 \mathrm{~d}$ resulted in consistent achievement of target exposures associated with neuroprotection in animal models of hypoxic-ischemic brain injury. These findings support the use of this Epo dosing strategy for future efficacy studies in neonates with HIE receiving hypothermia.

\section{SUPPLEMENTARY MATERIAL}

Supplementary material is linked to the online version of the paper at http:// www.nature.com/pr

\section{ACKNOWLEDGMENTS}

The authors thank Krisa Van Meurs, MD for her overall guidance and perspective in support of the study and Jessica Kan Vedder, BA, MPH for her organizational support of the study, for creating the study database, and for her work in monitoring enrollment and data collection procedures. The authors thank Zahra Afsharinejad, MS and Pat Janssen, MS for performing the MSD Epo assay and corresponding Epo data collection. The authors thank the following collaborators who enrolled patients or assisted with the design of the phase I and phase II studies: Roberta Ballard, MD, Sonia Bonifacio, MD, Taeun Chang, MD, Lawrence Dong, MD, David Durand, MD, Donna Ferriero, MD, Hannah Glass, MD, Fernando Gonzalez, MD, Amit Mathur, MD, Dennis Mayock, MD, MD, Sarah Mulkey, MD, Elizabeth Rogers, MD, Dongli Song, MD, Krisa Van Meurs, MD. The authors would also like to thank all the patients, families, and bedside nurses who participated in this study. Study data were collected and managed using REDCap electronic data capture tools hosted at University of California, San Francisco.

\section{STATEMENT OF FINANCIAL SUPPORT}

A.F. is funded by Eunice Kennedy Shriver National Institute of Child Health and Human Development K23HD079557. The phase I and phase II clinical studies were funded by the Thrasher Research Fund, Salt Lake City, UT and the Cerebral Palsy Alliance Research Foundation, Allambie Heights, Australia.

Disclosure: The authors have no conflict of interest, real or perceived, to report.

\section{REFERENCES}

1. Perlman JM, Wyllie J, Kattwinkel J, et al.; Neonatal Resuscitation Chapter Collaborators. Part 11: Neonatal resuscitation: 2010 International consensus on cardiopulmonary resuscitation and emergency cardiovascular care science with treatment recommendations. Circulation 2010;122(16 Suppl 2):S516-38.

2. Gluckman PD, Wyatt JS, Azzopardi D, et al. Selective head cooling with mild systemic hypothermia after neonatal encephalopathy: multicentre randomised trial. Lancet 2005;365:663-70.

3. Jacobs SE, Morley CJ, Inder TE, et al.; Infant Cooling Evaluation Collaboration. Whole-body hypothermia for term and near-term newborns with hypoxic-ischemic encephalopathy: a randomized controlled trial. Arch Pediatr Adolesc Med 2011;165:692-700.

4. Simbruner G, Mittal RA, Rohlmann F, Muche R; neo.nEURO.network Trial Participants. Systemic hypothermia after neonatal encephalopathy: outcomes of neo.nEURO.network RCT. Pediatrics 2010;126:e771-8.
5. Azzopardi DV, Strohm B, Edwards AD, et al.; TOBY Study Group. Moderate hypothermia to treat perinatal asphyxial encephalopathy. N Engl J Med 2009;361:1349-58.

6. Shankaran S, Pappas A, McDonald SA, et al.; Eunice Kennedy Shriver NICHD Neonatal Research Network. Childhood outcomes after hypothermia for neonatal encephalopathy. N Engl J Med 2012;366:2085-92.

7. Kumral A, Ozer E, Yilmaz O, et al. Neuroprotective effect of erythropoietin on hypoxic-ischemic brain injury in neonatal rats. Biol Neonate 2003;83:224-8.

8. Kumral A, Uysal N, Tugyan K, et al. Erythropoietin improves long-term spatial memory deficits and brain injury following neonatal hypoxia-ischemia in rats. Behav Brain Res 2004;153:77-86.

9. Matsushita H, Johnston MV, Lange MS, Wilson MA. Protective effect of erythropoietin in neonatal hypoxic ischemia in mice. Neuroreport 2003;14:1757-61.

10. Demers EJ, McPherson RJ, Juul SE. Erythropoietin protects dopaminergic neurons and improves neurobehavioral outcomes in juvenile rats after neonatal hypoxia-ischemia. Pediatr Res 2005;58:297-301.

11. Spandou E, Papadopoulou Z, Soubasi V, et al. Erythropoietin prevents long-term sensorimotor deficits and brain injury following neonatal hypoxia-ischemia in rats. Brain Res 2005;1045:22-30.

12. Sun Y, Calvert JW, Zhang JH. Neonatal hypoxia/ischemia is associated with decreased inflammatory mediators after erythropoietin administration. Stroke 2005;36:1672-8.

13. Kellert BA, McPherson RJ, Juul SE. A comparison of high-dose recombinant erythropoietin treatment regimens in brain-injured neonatal rats. Pediatr Res 2007;61:451-5.

14. Kumral A, Tüzün F, Oner MG, Genç S, Duman N, Ozkan H. Erythropoietin in neonatal brain protection: the past, the present and the future. Brain Dev 2011;33:632-43.

15. Zhu C, Kang W, Xu F, et al. Erythropoietin improved neurologic outcomes in newborns with hypoxic-ischemic encephalopathy. Pediatrics 2009;124:e218-26.

16. Elmahdy H, El-Mashad AR, El-Bahrawy H, El-Gohary T, El-Barbary A, Aly H. Human recombinant erythropoietin in asphyxia neonatorum: pilot trial. Pediatrics 2010;125:e1135-42.

17. Wu YW, Mathur AM, Chang T, et al. High-dose erythropoietin and hypothermia for hypoxic-ischemic encephalopathy: a phase II trial. Pediatrics 2016;137:e20160191.

18. Frymoyer A, Meng L, Bonifacio SL, Verotta D, Guglielmo BJ. Gentamicin pharmacokinetics and dosing in neonates with hypoxic ischemic encephalopathy receiving hypothermia. Pharmacotherapy 2013;33:718-26.

19. Frymoyer A, Lee S, Bonifacio SL, et al. Every 36-h gentamicin dosing in neonates with hypoxic-ischemic encephalopathy receiving hypothermia. J Perinatol 2013;33:778-82.

20. Frymoyer A, Bonifacio SL, Drover DR, Su F, Wustoff CJ, Van Meurs KP. Decreased morphine clearance in neonates with hypoxic ischemic encephalopathy receiving hypothermia. J Clin Pharmacol 2017;57:64-76.

21. Statler PA, McPherson RJ, Bauer LA, Kellert BA, Juul SE. Pharmacokinetics of high-dose recombinant erythropoietin in plasma and brain of neonatal rats. Pediatr Res 2007;61:671-5.

22. Wu YW, Bauer LA, Ballard RA, et al. Erythropoietin for neuroprotection in neonatal encephalopathy: safety and pharmacokinetics. Pediatrics 2012;130:683-91.

23. Shankaran S, Laptook AR, Ehrenkranz RA, et al.; National Institute of Child Health and Human Development Neonatal Research Network. Whole-body hypothermia for neonates with hypoxic-ischemic encephalopathy. N Engl J Med 2005;353:1574-84.

24. Veng-Pedersen P, Widness JA, Pereira LM, Schmidt RL, Lowe LS. A comparison of nonlinear pharmacokinetics of erythropoietin in sheep and humans. Biopharm Drug Dispos 1999;20:217-23.

25. Widness JA, Veng-Pedersen P, Peters C, Pereira LM, Schmidt RL, Lowe LS. Erythropoietin pharmacokinetics in premature infants: developmental, nonlinearity, and treatment effects. J Appl Physiol (1985) 1996;80: $140-8$.

26. Juul SE, McPherson RJ, Bauer LA, Ledbetter KJ, Gleason CA, Mayock DE. A phase I/II trial of high-dose erythropoietin in extremely low birth weight infants: pharmacokinetics and safety. Pediatrics 2008;122:383-91. 


\section{Articles | Frymoyeretal.}

27. Anderson BJ, Holford NH. Mechanism-based concepts of size and maturity in pharmacokinetics. Annu Rev Pharmacol Toxicol 2008;48: 303-32.

28. Holford N, Heo YA, Anderson B. A pharmacokinetic standard for babies and adults. J Pharm Sci 2013;102:2941-52.

29. Brendel K, Comets E, Laffont C, Mentré F. Evaluation of different tests based on observations for external model evaluation of population analyses. J Pharmacokinet Pharmacodyn 2010;37:49-65.

30. Comets E, Brendel K, Mentré F. Computing normalised prediction distribution errors to evaluate nonlinear mixed-effect models: the npde add-on package for R. Comput Methods Programs Biomed 2008;90:154-66.

31. Zanelli S, Buck M, Fairchild K. Physiologic and pharmacologic considerations for hypothermia therapy in neonates. J Perinatol 2011;31:377-86.

32. Jelkmann $\mathrm{W}$. The enigma of the metabolic fate of circulating erythropoietin (Epo) in view of the pharmacokinetics of the recombinant drugs rhEpo and NESP. Eur J Haematol 2002;69:265-74.

33. Nalbant D, Saleh M, Goldman FD, Widness JA, Veng-Pedersen P. Evidence of receptor-mediated elimination of erythropoietin by analysis of erythropoietin receptor mRNA expression in bone marrow and erythropoietin clearance during anemia. J Pharmacol Exp Ther 2010;333:528-32.

34. Chapel SH, Veng-Pedersen P, Schmidt RL, Widness JA. Receptor-based model accounts for phlebotomy-induced changes in erythropoietin pharmacokinetics. Exp Hematol 2001;29:425-31.

35. Roberts JK, Stockmann C, Ward RM, et al. Population pharmacokinetics of darbepoetin alfa in conjunction with hypothermia for the treatment of neonatal hypoxic-ischemic encephalopathy. Clin Pharmacokinet 2015;54:1237-44.

36. Warwood TL, Ohls RK, Lambert DK, et al. Intravenous administration of darbepoetin to NICU patients. J Perinatol 2006;26:296-300.
37. Lee BF, Wang LW, Lin SH, et al. Tc-99m-HL91 imaging in the early detection of neuronal injury in a neonatal rat model of hypoxic ischemia. Crit Care Med 2012;40:1930-8.

38. Muramatsu K, Fukuda A, Togari H, Wada Y, Nishino H. Vulnerability to cerebral hypoxic-ischemic insult in neonatal but not in adult rats is in parallel with disruption of the blood-brain barrier. Stroke 1997;28:2281-8; discussion 2288-9.

39. Plateel M, Teissier E, Cecchelli R. Hypoxia dramatically increases the nonspecific transport of blood-borne proteins to the brain. J Neurochem 1997;68:874-7.

40. Xenocostas A, Cheung WK, Farrell F, et al. The pharmacokinetics of erythropoietin in the cerebrospinal fluid after intravenous administration of recombinant human erythropoietin. Eur J Clin Pharmacol 2005;61:189-95.

41. Juul SE, McPherson RJ, Farrell FX, Jolliffe L, Ness DJ, Gleason CA. Erytropoietin concentrations in cerebrospinal fluid of nonhuman primates and fetal sheep following high-dose recombinant erythropoietin. Biol Neonate 2004;85:138-44.

42. Iwai M, Stetler RA, Xing J, et al. Enhanced oligodendrogenesis and recovery of neurological function by erythropoietin after neonatal hypoxic/ischemic brain injury. Stroke 2010;41:1032-7.

43. Reitmeir R, Kilic E, Kilic U, et al. Post-acute delivery of erythropoietin induces stroke recovery by promoting perilesional tissue remodelling and contralesional pyramidal tract plasticity. Brain 2011;134(Pt 1):84-99.

44. Larpthaveesarp A, Georgevits M, Ferriero DM, Gonzalez FF. Delayed erythropoietin therapy improves histological and behavioral outcomes after transient neonatal stroke. Neurobiol Dis 2016;93:57-63.

45. Baserga MC, Beachy JC, Roberts JK, et al. Darbepoetin administration to neonates undergoing cooling for encephalopathy: a safety and pharmacokinetic trial. Pediatr Res 2015;78:315-22. 